Croma. El color que alguna vez fue vivaz y precioso

Eva Beatriz Noriega

Arkadin (N. ${ }^{\circ} 8$ ), e012, agosto 2019. ISSN 2525-085X

https://doi.org/10.24215/2525085Xe012

http://papelcosido.fba.unlp.edu.ar/ojs/index.php/arkadin

Facultad de Bellas Artes. Universidad Nacional de La Plata

La Plata. Buenos Aires. Argentina

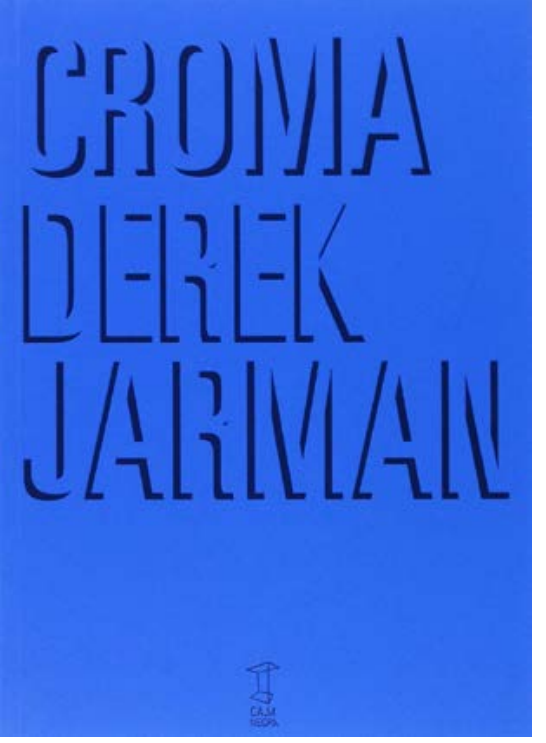

\title{
CROMA
}

\section{El color que alguna vez fue vivaz y precioso}

\section{Croma}

\author{
The Colour that Was Vivacious and \\ Precious
}

\section{EVA BEATRIZ NORIEGA}

screeners@fba.unlp.edu.ar

Instituto de Investigación en Producción y Enseñanza de Arte Argentino y Latinoamericano.

Facultad de Bellas Artes. Universidad Nacional de La Plata. Argentina

Reseña a Derek Jarman (2017). Croma. Un libro de color. Ciudad Autónoma de Buenos Aires, Argentina: Caja Negra, 235 páginas.

Recibido 8/3/2019 | Aceptado 20/6/2019

\section{RESUMEN}

Croma. Un libro de color (2017) consiste en el último libro escrito por el cineasta de culto Derek Jarman, en los últimos meses de vida, víctima del SIDA. Una autobiografía de retazos que indaga en la combinación cromática de los colores, su historia cultural y su propia experiencia sensible del color.

\section{PALABRAS CLAVE}

Cine; color; cine queer; cine experimental

\section{ABSTRACT}

Croma. A book of color (2017) consists in the last book written by famous cult filmmaker Derek Jarman during the last months of his life, victim of AIDS. An autobiography made of scraps inquiring in chromatic combination of colors, their cultural history and his own sensible experience of color.

\section{KEYWORDS}

Cinema; color; queer cinema; experimental cinema 
Croma. Un libro de color es el título del último libro escrito por Derek Jarman que se publicó en 1994. En 2017 la editorial Caja Negra presentó Croma, una traducción de Hugo Salas dentro de la colección Synesthesia (235 páginas). En el prólogo su traductor, quien es además conocido como escritor y crítico de cine ensaya una sucinta descripción del recorrido de la filmografía de Jarman en Buenos Aires y en el mundo de habla hispana, comentando que su cine ha sido poco visto con escasa presencia en la cartelera de estrenos comerciales y fue tratado con cierta indiferencia por la crítica. Lo que descubrimos con este libro revelador, es a una personalidad dotada de una imaginación y una sensibilidad queer sin límites que supo practicar junto al arte de la pintura y al cinematográfico el oficio de la escritura.

El título del libro de Jarman incluye una descripción: «Un libro de color», la cual, comenta Rocío Saucedo Dimas (2005), instruye claramente al lector sobre el propósito de la obra. Asimismo, como mencionamos anteriormente, la edición cuenta con un ensayo especialmente anotado a cargo de Hugo Salas, que funciona como anticipación no solo del libro sino de su autor, cineasta, pintor, poeta, y de una poética que se desliza entre sus películas, sus obras inconclusas y su militancia queer. Salas introduce al autor:

Para el público de masas, era demasiado raro. Para la cultura oficial, muy politizado. Para los cinéfilos, «culturoso». Para los refinados, de mal gusto. Para la izquierda, antipopular. Para la derecha, inaceptable. En fin... lo que suele ocurrirle al cine de barricada, obligado a construir su público en el marco de una pequeña comunidad de afines (p. 9).

Le sigue una introducción del propio Jarman y los 19 capítulos que conforman este texto, que incluye referencias a la historia del arte y a la literatura clásica, al origen de los colores y al sentido dado a los colores en la cultura occidental y en sus propias películas, que se expresan como una búsqueda de color. Es decir, todo aquello que puede poner en tensión el color. Sin embargo, como afirma Laura Gutiérrez (2018):

Croma no es entonces un libro sobre el color, tampoco del color. Es un libro de color de un artista multifacético que escribe la memoria sensible de las tonalidades cromáticas mientras se está quedando ciego por causas del virus de vih+, virus que contrajo en 1986 y que produjo, casi como marca de época, un cuerpo en frenesí. Entre 1986 y 1993, un año antes de su muerte, Jarman escribió, filmó y produjo seis largometrajes: Caravaggio (1986); The Last of England (1987); War Requiem (1989); The Garden (1990); Eduardo II (1991); Wittgenstein y Blue (1993) y la póstuma Glitterbug (1994) que recupera una serie de filmaciones en Super 8 a lo largo de su vida. A ellas se suman sus ya clásicas Sebastiane (1976), Jubilee (1976); The Tempest (1979), Imagining October (1984) y The Angelic Conversation (1985). Además, pintó grandes cuadros, acercándose y experimentando cada vez más con la ironía, el color, la enfermedad y la pintura. Una serie de imágenes que dialogan con el activismo de Act Up y las obras The General Idea y de David Wojnarowicz (s. p.).

A esta lista se deben sumar los videos musicales producidos junto con algunas de las bandas británicas pop y punk más destacadas de los años ochenta: The Queen is Dead, Panic, There is a Light That Never Goes Out, Ask (alrededor de 1986) para The Smiths; Dance Hall Days de Wang Chung; It's A Sin de Pet Shop Boys, entre otros. También se deben incluir los cortos Broken English (1979), filmados para la presentación de tres canciones de Marianne Faithful, y el trabajo en colaboración con Annie Lennox, quien interpreta Every Time We Say Goodbye en su película Edward II (1991).Además de ser un conocido cineasta y pintor, que se inició en el cine primero como escenógrafo, Jarman escribió varios volúmenes publicados como los diarios de Derek Jarman entre los cuales: Modern Nature (1991) cuenta con una flamante traducción por la misma editorial Caja negra bajo el título Naturaleza Moderna (20129). Otros de sus libros póstumos son Smiling in Slow Motion (1994), At your own risk (1992), Dancing Ledge 
(1984), y The Derek Jarman's Garden (1995).

Croma, si bien parte de una búsqueda del color, también puede considerarse una reelaboración de aquellos diarios, ya que la dimensión política de su enfermedad, la invisibilización de la cultura gay así como su reflexión sobre personajes históricos y amigos recorre todos los capítulos. De ahí que otro de los elementos centrales del texto se asienta en lo autobiográfico. Jarman relata a lo largo del texto experiencias personales siempre relacionadas con algún color determinado. Del capítulo dedicado al azul, «Hacia el Azul», extrajo casi íntegramente el escrito que después se convertiría en el relato de la película Blue (1993). A su vez, gran parte del texto contenido en «Hacia el Azul» proviene de algunas anotaciones hechas en el diario del autor durante agosto de 1992. Los diarios escritos por Jarman -treinta y tres cuadernos en total- fueron, al menos parcialmente, publicados.

La edición de Caja Negra se puede concebir, además, como un homenaje a Blue, el guión que sirvió de base para su película y la película misma, ya que es el color de la portada del libro y, a su vez, incluye hojas de ese color como separación entre los capítulos. Si bien es difícil reconocer a simple vista si se trata del pigmento azul Klein creado o rebautizado así por el artista conceptual Ives Klein, se puede afirmar que su presencia refiere a la única imagen fija que hace de fondo de su película Blue cuyo lenguaje visual es una referencia explícita al color, como evocación del vacío y de zonas de inmaterialidad que Klein atribuía a su estética del azul.

Esta película de 79 minutos de duración se inscribe en un lenguaje claramente de cine experimental, que se despliega sobre un fondo de color fijo y está narrada desde el sonido por la voz over de los personajes (de Derek Jarman y de una amiga) y a través de la banda sonora. El texto que se oye es una mezcla de diario y de pasajes poéticos, documenta su vida en los últimos meses de convivencia con el SIDA, su experiencia de ir quedándose parcialmente ciego. Jarman revisa su pasado como artista y militante queer. La obra se estrena apenas unos meses antes de su muerte.

En ese sentido, el Jarman cineasta, militante y provocador es inseparable del escritor. Como revela Salas (en Jarman, 2017) acaso el mayor problema para la recepción de su cine:

[...] haya tenido que ver con que no aceptó ninguna de las vías toleradas para la representación de la homosexualidad: ni el refinamiento silencioso de un Visconti, ni la experiencia tortuosa y oscura de un Fassbinder, ni el freak show de La jaula de las locas, ni mucho menos el modelo gay del blanco profesional encantador y sentimental pregonado por la buena conciencia de Hollywood (p. 10).

Las últimas películas, las mejores de su carrera, están asoladas por el fantasma de la muerte: en 1986 Derek Jarman recibe su diagnóstico de VIH. A diferencia de lo que solía ocurrir con las personalidades públicas, que se retiraban para tratarse, él decidió hacerlo público y convertirse en una de las pocas figuras en presentarse ante los medios como un paciente de la enfermedad que en ese momento aterrorizaba a millones. Tilda Swinton (en Jarman, 2017) observó que, devastado en lo personal, como artista, Jarman consideró a la enfermedad un desafío formidable y abordó su propia muerte a la manera de una obra de arte.

Algo de ello se advierte en este libro, lo que lo convierte en un texto único del siglo XX. Elegíaco, nostálgico, apasionado, contestatario, enojado... Croma establece con su lector una intimidad imposible y por momentos intolerable, que llega a su paroxismo en el capítulo «Hacia el azul». No debe habérsele escapado la ironía de un libro sobre el color escrito por alguien que estaba quedándose ciego. Sin prisa, Jarman se va despidiendo de él, como así también de los libros, de su jardín y de las plantas, del pasado, del sexo, de sus amigos, de la vida. En la descripción de cada pigmento se deja oír 
el amor de quien sabe que no volverá a mezclarlos. En cada recuerdo, el reconocimiento de que han de perderse con él. Su lucidez ante la muerte, su falta de compasión, su humor implacable -el título de uno de sus últimos cuadros, expuesto hoy en la Tate Gallery, es Ataxia, el sida es divertido, haciendo alusión a la pérdida de coordinación motriz inducida por los medicamentos-, hacen de la lectura de Croma una experiencia tan intensa como lacerante.

Sin embargo, las rutas de acceso al tema incorporan a la vez múltiples discursos y registros. En términos de arquitectura textual y gama de contenidos, se trata de un texto proteico: transita del verso a la prosa, de la ficción historiográfica a lo estrictamente lírico, de lo anecdótico a la cita textual de diversos autores, de Aristóteles a Kazimir Malevich. El autor aborda el tema del color desde diferentes perspectivas: la pintura, el cine, la literatura, la filosofía, la ciencia, etcétera. Para Laura Gutiérrez (2018) se trata de un cuaderno que desafía la ceguera - de la historia, de la retina- sostenido en el amor, en el afecto de sus amigas y amigos, y en Kevin Collins (HB en el libro), su último compañero.

En algunos capítulos se puede seguir su aventura sobre los colores, como en «Los peligros del amarillo». En ellos se atenúan las repercusiones en relación con su experiencia de vida, pero se acentúan los vínculos con su filmografía, en la que la búsqueda de los colores constituye parte del trabajo creativo. Como cuando Jarman (2017) afirma:

El amarillo estimula una impresión cálida y agradable. Un paisaje visto a través de un vidrio amarillo resulta agradable al ojo. En muchos de los planos que filmé en Dungeness para The Garden (su largometraje de 1999) con mi cámara de Super 8 usé para el cielo un filtro amarillo. Produjo efectos otoñales (p. 150).

En «Artes negras o Mi Anima Nera» aborda la infinitud del negro y afirma: «En el fuego del negro carbón vive el espíritu del arte de contar historias. Temblorosas llamas de color azul y escarlata. Fue en torno al fuego, de noche, que los hombres y mujeres comenzaron a contarse historias, en medio de una oscuridad de alquitrán» (Jarman, 2017, p. 222).

En ciertos pasajes el color reivindica una experiencia atravesada por la sensibilidad, una puerta al mundo de los sentidos que estimulan en el lector lo plástico y lo táctil «el negro terciopelo, un labial escarlata» o el gusto: «el azafrán y la cúrcuma son naranjas», y en otros se revela el conocimiento estético y científico a través de las palpitaciones del ojo cuando evoca las «pompas de jabón arcoíris» o viejas fórmulas de color. Una visita al mundo de la infancia, el descubrimiento de la pintura o la televisión. Una forma de nombrar los límites de lo permitido y a la vez las «zonas rojas» que abren paso al deseo, como afirma en «Sobre ver rojo»:

El rojo es un momento en el tiempo. El azul es constante. El rojo se gasta rápido. Una explosión de intensidad. Se quema a sí mismo. Desaparece como las chispas encendidas que saltan hacia la densa oscuridad. Necesitamos algo de calor durante el largo y sombrío invierno en que el rojo no está (Jarman, 2017, p. 71).

Un libro fascinante e inclasificable, un tratado autorreflexivo y teórico, donde los colores como la piel «rechazan el mundo» y abrazan el lenguaje para dejar testimonio de la existencia.

\section{REFERENCIAS}

Gutiérrez, L. (2018). Un ensayo cromático sobre el ardor de estar vivxs. Bazar Americano, 11(68). Recuperado de http://www.bazaramericano.com/resenas. php?cod=803\&pdf=si

Jarman, D. (2017). Croma. Un libro de color. Ciudad Autónoma de Buenos Aires, Argentina: Caja Negra. 
Saucedo Dimas, R. (2005). La imagen escrita. Los imaginarios del colory del sujeto en un texto de Derek Jarman (Tesis de licenciatura). Facultad de Filosofia y Letras de la Universidad Nacional Autónoma de México, Ciudad de México, México. Recuperado de https://repositorio.unam.mx/contenidos/laimagen-escrita-los-imaginarios-del-color-y-del-sujeto-en-un-texto-de-derek-jarman-146002?c=pQ8 wXB\&d=false\&q=saucedo_._dimas $\&=1 \& v=1 \& \mathrm{t}=$ search_o\&as=0 